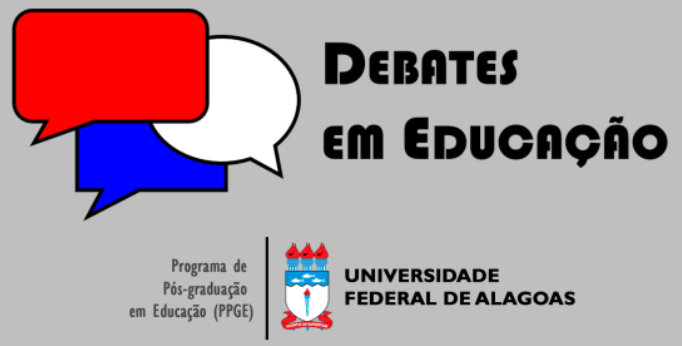

ISSN Eletrônico 2175-6600

Vol. 12 | Número Especial | 2020

Ricardo Jorge de Sousa Cavalcanti 9 iD

Instituto Federal de Alagoas (IFAL) richardcavalcanti@hotmail.com

Lúcia de Fátima Santos

(9) iD

Universidade Federal de Alagoas (UFAL) lfsmar@hotmail.com

\section{A ARGUMENTAÇÃO NO PROCESSO DE FORMAÇÃO INICIAL DOCENTE: REFLEXÕES DOS EGRESSOS DO PIBID LETRAS/PORTUGUÊS DA UNIVERSIDADE FEDERAL DE ALAGOAS}

\section{RESUMO}

$\bigcirc$ trabalho analisa o ethos, num viés retórico-enunciativo, de egressos do PIBID, Subprojeto Letras, da Universidade Federal de Alagoas (UFAL). A abordagem metodológica é qualitativa numa análise linguístico-interpretativista, recorrendo-se a Notas de Campo (NC) dos sujeitos à época em que faziam parte do PIBID, como bolsistas de Iniciação à Docência; e tem como perspectiva reconhecer os seus Ethe, mediante as implicações desse Programa em suas práticas autorreflexivas como professores em formação inicial. Estudos sobre o letramento do professor (FIAD, 2011; KLEIMAN; DIAS, 20I6; SANTOS; 20I2), no campo multidisciplinar da Linguística Aplicada (MOITA-LOPES, 2006); a Argumentação Retórica (PERELMAN; OLBRECHTS-TYTECA, 2005; REBOUL, 2004; MEYER, 2008) e a Argumentação na Língua (DUCROT, 1987; KOCH, 2008), e os estudos sobre os saberes profissionais docentes (TARDIF, 20l4) são caros ao empreendimento das análises neste estudo. Os resultados apontam para a importância do desenvolvimento de práticas de escrita reflexiva nos processos de letramento acadêmico e docente desses sujeitos.

Palavras-chave: Ethos. Argumentação. Letramento docente.

\section{ARGUMENTATION IN THE INITIAL TEACHING TRAINING PROCESS: REFLECTIONS OF PORTUGUESE LANGUAGE GRADUATES FROM PIBID AT UNIVERSIDADE FEDERAL DE ALAGOAS}

\footnotetext{
ABSTRACT

The paper analyzes the rhetorical-enunciative process ethos of graduated from PIBID, Subproject Portuguese Language, at Universidade Federal de Alagoas (UFAL). The methodological approach is qualitative in a linguistic-interpretative analysis, using Field Notes (FN) of the subjects at the time when they were participating in PIBID, as scholarships for Initiation to Teaching, and it aims to recognize its Ethe, considering the implications of this Program in their self-reflexive practice as teachers in the initial education. In the field of multidisciplinary Applied Linguistics (MOITA-LOPES, 2006), the teachers' literacy studies (FIAD, 20I I; KLEIMAN e DIAS, 20 I 6; SANTOS, 20I 2); the Rethoric Argumentation studies (PERELMAN; OLBRECHTS-TYTECA 2005; REBOUL, 2004; MEYER, 2008); the Linguistic Argumentation studies (DUCROT, 1987; $\mathrm{KOCH}, 2008)$, the studies aimed at the teachers' professional knowledge (TARDIF, 20I4), are important to undertaking of the analyzes in this study. The results point to the importance of developing reflexive writing practices in the academic and teaching literacy processes of these subjects.
}

Keywords: Ethos. Argumentation. Teaching literacy.

Submetido em: 24/04/2020

Aceito em: 27/05/2020

Publicado em: 10/12/2020

d. http://dx.doi.org//0.28998/2175-6600.2020v I 2nEspp246-262 


\section{INTRODUÇÃO}

O presente estudo é um recorte de uma pesquisa de estágio pós-doutoral (20 I 9), cuja motivação se deu com base nas experiências dos pesquisadores no âmbito da formação de professores de Língua Portuguesa e, em especial, a partir de suas experiências no Programa Institucional de Iniciação à Docência - PIBID, como Coordenadores de Área Língua Portuguesa, nos loci do Instituto Federal de Alagoas - IFAL e da Universidade Federal de Alagoas - UFAL. Ao se iniciar tal investigação, intencionamos, a partir de dispositivos teórico-conceituais da Linguística Aplicada, doravante LA - área da Linguística que se firma por sua hibridização epistemológica -, da Linguística Textual, da Nova Retórica, da Teoria da Argumentação na Língua (TAL), dos Letramentos Acadêmico e Docente e dos Saberes Profissionais Docentes, refletir como se deu (e ainda se dá) a argumentação nos processos reflexivos, tanto na perspectiva retóricodiscursiva quanto na linguístico-enunciativa, dos sujeitos egressos do PIBID, vinculados à época ao Campus A.C. Simões, da UFAL, no período compreendido entre os anos de 2010 a 2014.

Ademais, há de se considerar a forma enunciativo-argumentativa escrita desses egressos sujeitos nas suas atuais condições de docentes, nas redes públicas e privadas de ensino de Alagoas, em relação às contribuições de tal Programa para a sua prática pedagógica. As argumentações correspondentes a esses dois momentos foram analisadas com base nos seguintes instrumentos de investigação: I- Notas de Campo (NC), produzidas nos momentos em que os sujeitos faziam parte do PIBID, considerando os círculos reflexivos de que participavam, mediados pela Coordenação de Área, e as suas enunciações a respeito das práticas, como pibidianas, nas escolas campo de atuação desse Programa (dados em foco de discussão neste artigo); e 2- Questionário aberto, respondido pelos sujeitos da investigação, sendo elaborado em razão das finalidades do estudo, principalmente, no que diz respeito à emissão de juízos de valor nos quais podem ser reconhecidos seus Ethe docentes, por meio de dispositivos retórico-discursivos e linguístico-enunciativos, (dados que não serão discutidos neste trabalho, por razão de espaço). A categoria do ethos, em relação às reflexões sobre a docência, é considerada como essencial em nossa investigação.

Com efeito, neste trabalho, considerando a inter-relação com o objetivo central traçado para proceder ao presente estudo, lançamos as seguintes perguntas: I - Como são utilizadas, no plano retóricoargumentativo e linguístico-discursivo, as estratégias para sustentar as teses desses egressos na defesa de seus pontos de vista demonstrados/formulados em NC? 2- Quais são as concepções que têm esses egressos sobre língua(gem), sujeito, ensino das modalidades, leitura e ensino dos gêneros, a partir de suas atuações como bolsistas do PIBID? 3- Quais são as implicações dessas concepções para as suas práticas pedagógicas no contexto da educação básica, isto é, para a sua formação docente? Tais questionamentos serão respondidos 
na proporção das análises empreendidas pelos pesquisadores, de modo que serão dispostos na parte destinada às considerações finais deste estudo.

Com a pretensão de situar o leitor acerca da organização deste texto, a princípio, com base no campo conceitual em que nos situamos, neste caso, a LA, tratamos dos estudos dos letramentos e de sua inter-relação, neste objeto de discussão, com a argumentação nos planos retórico-discursivo e linguísticoenunciativo; em seguida, abordamos a metodologia a que nos filiamos para o empreendimento desta investigação, que se assume como qualitativa, numa abordagem linguístico-interpretativista de análise, conjugada aos respectivos instrumentos de coleta de dados; e, em última instância, atemo-nos à disposição e à análise dos dados na perspectiva de refletir sobre alguns de nossos achados da pesquisa. ${ }^{1}$

\section{LETRAMENTOS: DESDOBRAMENTOS TEÓRICO-CONCEITUAIS}

O termo letramento ocupa um considerável espaço de discussão na esfera acadêmico-científica, sobretudo na didática, ao tratar do letramento do professor (KLEIMAN; ASSIS, 20 I6). Essa perspectiva visa a um entendimento acerca do sujeito professor como um agente de letramento, inserido em práticas sociais diversificadas, estabelecendo uma interação entre eventos hierarquizados pelas instâncias de poder, considerados eruditos nas esferas escolar e acadêmica, àqueles que fazem parte dos seus eventos mais cotidianos. Tal abordagem epistemológica tem se dado em materiais didáticos, cuja terminologia - embora, por vezes, sem muita clareza discursiva - é evocada; além de discussões presentes em contextos formativos docentes, geralmente alinhadas às bases político-pedagógicas dos cursos de formação de professores de línguas com vistas a compreender esses sujeitos como agentes de letramento.

Ante a isso, existem discussões sobre letramento numa perspectiva mais clássica, geralmente ligada às práticas de alfabetização; e a perspectiva mais contemporânea, a dos Novos Estudos do Letramento, que tem desdobramentos que atendem, inclusive, ao campo de formação inicial e continuada docente. Assim, os Novos Estudos do Letramento, doravante NEL (NLS²), ensejam a consideração dos aspectos sociais, culturais e antropológicos de sujeitos inseridos em práticas socioculturais diversificadas, permeadas por inúmeros eventos de letramento. Possivelmente, em razão da ampliação dessa discussão, o termo letramento, atualmente, tem carregado uma multiplicidade de sentidos, visto que, a partir disso, não deve ser concebido como um mero recurso de sufixação (letramentos), como bem assevera Rojo (2009a;

\footnotetext{
'- Esta investigação teve a sua submissão ao Comitê de Ética local (CEP), cujo parecer de aprovação está disposto na Plataforma Brasil, sob o n. 3.375.593. Cabe salientar que esta pesquisa primou pelos princípios éticos necessários à sua aprovação, conforme preconiza a Res. CNS 466/20 I2, incluindo, para participação dos sujeitos colaboradores, a adesão voluntária por meio do TCLE.

2. NLS - New Literacy Studies - Perspectiva proposta por estudiosos anglo-saxões, mas que no Brasil gera divisão de opiniões quanto a essa terminologia, já que esses estudos, aqui, não possuem antecessores, dado que o seu aparecimento se dá mais precisamente na década de 1990, prevalecendo, assim, a terminologia os estudos do letramento (cf.KLEIMAN, 1995).
} 
2009b), mas como uma perspectiva que se imbrica em variados campos de atuação humana, cujas práticas sociais envolvem atividades de leitura e de escrita, vislumbrando-se os seus agentes e suas práticas linguageiras.

Acerca disso, compreendemos que o trabalho com os gêneros discursivos em sala de aula, almejando-se uma perspectiva de letramento pautada mais no modelo ideológico, deve levar em conta, haja vista que esses artefatos linguístico-discursivos se apresentam (refletindo-se e refratando-se) em eventos variados nas distintas atividades de atuação humana (BAKHTIN, 2003), que estão dispostas em práticas situadas de letramento, e que a escola e a universidade, concebidas como agências formais, devem considerá-los para além dos cânones.

No que diz respeito às modalidades de uso da língua, Street (2014) advoga, com vistas aos letramentos sociais, que a oralidade é tão importante quanto a escrita, e que a aquisição da escrita não confere a uma sociedade, tampouco a um sujeito, graus de abstração mais elevados quando comparados a sujeitos cujo domínio da escrita não é evidenciado, como é o caso de comunidades de cultura ágrafa. Reconhecemos o legado de Street (2014) ao se posicionar que não é o domínio exclusivo da modalidade escrita que confere ao sujeito um trânsito diferenciado socialmente; mas, sobremaneira, os eventos de letramento de que faz parte, o que pode lhe promover estratégias de ordem cognitiva mais consolidadas, inclusive as que possam lhe permitir uma atuação social mais crítico-reflexiva.

Os principais paradigmas de estudo do letramento são denominados por Street (1984) como "modelo autônomo" e "modelo ideológico". No modelo autônomo, sumariamente, há ênfase nos processos de leitura e de escrita como habilidades pautadas no indivíduo. Nessa perspectiva, a escola ocupa um papel central, se não o único, para desenvolver no sujeito as habilidades de leitura e escrita. No modelo ideológico, assume-se uma perspectiva mais social em relação ao fenômeno do letramento, tendo em vista que a escola ocupa um papel importante no desenvolvimento das práticas de leitura e de escrita, mas não é a única agência, pois considera outras instâncias discursivas pelas quais o sujeito circula. Nesse prisma, o letramento é concebido como um fenômeno sociocultural, isto é, como um conjunto de atividades sociais que envolvem práticas multimodais em distintas agências de letramento que são acessadas correntemente pelos sujeitos.

\section{O LETRAMENTO DO PROFESSOR: REFLEXÕES ACERCA DA FORMAÇÃO INICIAL DO DOCENTE DE LÍNGUA PORTUGUESA}

Como vimos tratando nesta discussão, o modelo de letramento que se presta a desenvolver no sujeito uma reflexão mais acurada sobre os seus entornos - e mais que isso - e sobre o seu papel como sujeito responsivo ativo numa sociedade que cada vez mais se apresenta de forma multifacetada e de 
conceituações relativamente efêmeras é aquele que se relaciona mais ao modelo ideológico. Filiamo-nos a Street $(1984,2014)$, dessa forma, ao tratar que mesmo se considerando as limitações do modelo autônomo, existem atividades requeridas em contextos formais - escolares, acadêmicos e profissionais que preveem um conhecimento relativamente estereotipado acerca dessas demandas. Nesse âmbito, o conhecimento escolar e acadêmico requerido para a elaboração de gêneros, em atendimento à estrutura composicional, à forma e ao estilo (BAKHTIN, 2003) enseja, a nosso ver, o acesso tanto a um quanto a outro modelo.

Assim, seria interessante abordar que os modelos apresentados por Street (1984) se relacionam em práticas sociais que requerem a elaboração de eventos padronizados em atendimento a determinados fins, cuja produção confere por meio do acesso aos saberes universitários, adquiridos em processos de formação inicial e/ou continuada; aos saberes experienciais, baseados nos anos de experiência profissional, ou ainda, a partir de modelos anteriores com os quais nos filiamos em nossas práticas profissionais docentes atuais (TARDIF, 20|4), uma configuração de letramento docente. Em nosso entendimento, ao se considerar o sujeito professor em contato com práticas que lhe levem ao desenvolvimento de sua ação docente, as suas atitudes, as suas escolhas, os seus fazeres e as suas reflexões são elevadas ao plano subjetivo e, por isso, carecem de atitudes, por vezes, autônomas que asseveram aquilo de que tratamos a respeito da inter-relação entre os dois modelos de letramento - o autônomo e o ideológico.

Tardif (20 |4), a partir de estudos realizados, em contextos variados, tem reconhecido que o saber mais sobressaliente no plano do fazer laboral docente é o experiencial, pois, em contato com os pares, estes sujeitos se munem de conhecimentos para a tomada de atitudes em suas práticas docentes, uma vez que, segundo a realização de suas análises, a academia, ambiente institucionalizado e hierarquicamente superior de formação inicial docente, não subsidia elementos para lidar com os desafios cotidianos da docência - desde situações que se ligam à sala de aula a discussões que reverberam sobre os seus papéis em contextos sindicais, por exemplo. Em nossa discussão, primamos pela análise de práticas universitárias que desenvolvam o letramento acadêmico, e pela adoção das terminologias, em consonância com Vianna et al. (2016), letramento docente e/ou letramento do professor.

Vianna et al. (2016) alertam para a consideração dos saberes acadêmicos que serão apresentados no âmbito da formação inicial, além da consideração dos saberes pertencentes aos professores, a partir de outras práticas sociais, na introdução ou na ressignificação de eventos que visem ao desenvolvimento de seus letramentos acadêmicos.

No âmbito da formação inicial, a academia trabalha com professores em formação que tiveram nenhum ou pouco contato com o letramento acadêmico. Na formação continuada, por sua vez, a academia trabalha com professores que estão, em grande parte das vezes, distantes há um tempo considerável do letramento acadêmico. Daí a importância de uma formação que considere as especificidades desses sujeitos, seus objetivos com o curso de formação no qual se matriculam, 
as práticas de letramento que já vivenciam fora do meio acadêmico e aquelas que Ihes são totalmente novas (como aquelas das esferas profissionais), entre outros (VIANA et al.,20 I 6, p.5 I).

Não obstante, tenhamos a necessária consciência de que alguns gêneros acadêmicos, a exemplo do artigo científico - gênero bastante requerido ao desenvolvimento do letramento acadêmico em práticas universitárias -, serão concebidos como dispositivos linguístico-discursivos que suscitam análises críticoreflexivas para o empoderamento das práticas em seus fazeres cotidianos docentes.

\section{A CONSTITUIÇÃO DO ETHOS EM PROCESSOS ARGUMENTATIVOS NO LETRAMENTO DOCENTE}

Reconhecemos a importância de estudos que se prestem à argumentação em sua multiplicidade discursiva, tendo em vista que a concebemos como uma atividade inerente à linguagem humana, em afinidade com aquilo defendido por Ducrot (1987), para uma sucinta conceituação em relação à necessidade de estudos argumentativos à luz da Teoria da Argumentação na Língua (TAL), do ponto de vista linguístico-enunciativo. Esclarecemos que temos realizado pesquisas que dizem respeito à argumentação em práticas argumentativas, nas modalidades oral e escrita, tanto no âmbito da educação básica quanto no contexto do ensino superior (cf. CAVALCANTI, 20I0, 20 I6), na perspectiva da Nova Retórica, a partir de autores como Perelman e Olbrechts-Tyteca (2005 [1 958]); Reboul (2004 [1 998]); Meyer (2008), entre outros; e na abordagem linguístico-enunciativa, com base em Ducrot (1987), Koch (1987; 2008 [1984]), entre outros.

Para fins de delimitação de nosso objeto de estudo, centramos a nossa escolha teórica nas categorias da Nova Retórica, em especial, a categoria do ethos (eu), não deixando de considerar os demais elementos da tríade retórico-aristotélica, tais como: o pathos (tu) e o logos (ele), para uma articulação retórico-discursiva que considera o posicionamento do interlocutor, em processos de produção escrita, com vistas a um auditório particular e/ou universal. Ademais, relacionamos a categoria retórico-discursiva do ethos aos estudos que nos possibilitam compreender o Letramento Docente, a partir da reflexão sobre os saberes universitários - no contexto da formação inicial - àqueles que são mobilizados na atuação da prática de sala de aula no estabelecimento da relação teórico-prática (praxiológica) durante os momentos de que fizeram parte do Programa Institucional de Iniciação à Docência (PIBID).

Othos, categoria central de nosso estudo, pode ser entendido como pertencente à Retórica Clássica e que é retomado pela Nova Retórica, após o seu ressurgimento, em meados do século $X X$, com vistas à prospecção do sujeito a um auditório, dadas algumas condições de produção (CAVALCANTI, 2016). Esse sujeito, a partir da sua inserção no processo argumentativo, projeta-se com a intenção de convencer e/ou persuadir o outro, mobilizando conhecimentos de ordem linguístico-enunciativa e 
retórico-discursiva, no plano oral ou escrito - e ainda, vice-versa. Nessa relação interativa, o ethos, tendo em vista um pathos potencial, faz-se valer de elementos, inscritos na língua e, ainda, no plano retóricodiscursivo, para mostrar-se em atendimento ao seu propósito discursivo. A articulação desses saberes, com vistas a um auditório, pode ser entendida, sob a ótica dos estudos bakhtinianos, como um princípio de interação verbal, pois, ao tempo em que esse sujeito enuncia, anuncia-se, demarca-se nesse processo interativo (BAKHTIN, I98I [1979]; 2003 [1992]). É, nessa perspectiva, que tratamos da inter-relação estabelecida entre tais estudos retóricos e os discursivos.

Em correspondência com essas discussões sobre ethos numa perspectiva retórico-discursiva, concebemos os estudos do Letramento, de modo amplo, como práticas situadas de escrita e de leitura. Essa concepção é consensual entre os pesquisadores que refletem sobre o Letramento Docente. De um modo geral, os estudos que abordam letramento e formação do professor, desenvolvidos na área de Linguística Aplicada, como Kleiman (2001), Kleiman e Matêncio (2005), Kleiman e Baltar (2008), Fiad (20 I4), Signorini (2006), Vóvio, Sito e De Grande (2010), Santos (2007, 20 I 2), entre outros, discutem os impactos dos estudos do letramento para a formação de professores em acordo com uma concepção pluralista e multicultural das práticas de uso da escrita, mediante a focalização de atividades situadas (KLEIMAN, 200 I). Para isso, conjugam reflexões teóricas advindas de diversos campos de pesquisa, tal como se abordam nas orientações epistemológicas da LA.

Com base nas críticas existentes sobre a capacidade de o professor ensinar a ler e a escrever, como também sobre a sua própria condição de letrado, os estudos a respeito do letramento e da formação do professor propõem redirecionamentos importantes para o tratamento dessa questão com um enfoque bastante diferenciado daqueles que assumem um caráter meramente prescritivo. Entre as proposições dessa abordagem à parte sobre os usos e funções da escrita na formação dos professores, evidenciamos, como a mais relevante, o reconhecimento do professor como um sujeito participante de todo processo de reflexão sobre a sua formação, isto é, responsivo ativo em práticas de escrita reflexiva.

Kleiman (2005, p. 12), reunindo posições de diferentes pesquisadores, sintetiza essa proposta, ao afirmar que:

[...] a compreensão das ações de professoras, alfabetizadoras e agentes sociais envolve considerálas em relação à complexidade implicada no processo de construção de leitores e produtores de textos, de sujeitos da linguagem, em que estão envolvidos.

Essa autora chama atenção para a necessidade de não desmerecer "as ações desses sujeitos em razão das expectativas que as instituições de pesquisa e de formação criam a partir do modo como vão construindo seus objetos de estudo" (KLEIMAN, 2005, p. 12). Nesses termos, uma diversidade de fatores relacionados à constituição dos professores como sujeitos letrados tem sido abordada nos estudos sobre/do Letramento, como: as relações de poder que permeiam os usos da escrita; a construção da 
identidade profissional do professor; as representações do professor como leitor e produtor de textos; as implicações das abordagens das práticas de leitura e de escrita adotadas nos cursos de formação de professor; entre outras.

Os pesquisadores que refletem sobre essas questões reconhecem a necessidade de atrelar as discussões acerca das práticas de uso e funções da escrita nas relações sociais a uma concepção de linguagem correspondente. Sob esse enfoque, uma visão de linguagem como prática discursiva atende a esse objetivo, que é o de imbricar os usos da escrita e da leitura (também vistas como práticas discursivas) com os aspectos sociohistóricos e ideológicos. Fiad (201 I) enfatiza a importância dessa concepção de linguagem e de escrita como processos dialógicos na interação estabelecida entre os sujeitos nas suas histórias de escrita.

Desse modo, há de se ressignificar, para a presente discussão, o processo de letramento do professor, tomando como base de análise alguns preceitos voltados à argumentação, numa perspectiva retórico-discursiva, como é o caso do ethos. $\bigcirc$ estudo das concepções de língua(gem), a partir de passagens dispostas nas reflexões produzidas pelas pibidianas na modalidade escrita, também integra parte de nosso estudo nesta discussão. Os escritos desses sujeitos podem ser considerados não somente como enunciados referentes a etapas de participação no Programa, mas, sobretudo, como um posicionamento desses sujeitos em relação ao seu letramento docente durante essa etapa imprescindível aos seus percursos formativos.

\section{$5 \quad$ METODOLOGIA E INSTRUMENTOS DE COLETA DE DADOS}

As pesquisas de cunho interpretativista têm como propósito uma investigação contextual sobre a manifestação do objeto de estudo pretendido. Nessa perspectiva, elegemos a pesquisa linguísticointerpretativista, do tipo etnográfica, por acreditarmos que ela possibilita a compreensão de algumas práticas linguageiras argumentativas dos sujeitos ao contar com um arcabouço teórico-metodológico que, segundo Lüdke e André (1986, p. 17), “[...] seja capaz de reduzir o fenômeno em seus aspectos mais relevantes [...] a fim de melhor compreender e interpretar a realidade." Com efeito, a pesquisa em tela é de natureza qualitativa, pois visa à análise dos fenômenos pertencentes ao âmbito dos estudos de língua(gem), numa perspectiva social. As pesquisas de cunho qualitativo concebem os fatos e os fenômenos como significativos e relevantes, parafraseando Creswell (2007, p. 86).

A pesquisa qualitativa é, assim, mais participativa e, portanto, menos controlável. Os sujeitos podem, de certa forma, direcionar os rumos da pesquisa por meio de suas interações com o pesquisador. Esse tipo de investigação permite descrever melhor o que se faz pelo fato de se trabalhar com descrições, 
comparações e interpretações. $\bigcirc$ trabalho de descrição tem caráter fundamental em um estudo qualitativo, pois é por meio dele que os dados são coletados (MANNING, 1979 apud NEVES, 1996).

A elaboração de enunciações de teor argumentativo pelos sujeitos da pesquisa, relacionada às suas atuações como professores em formação inicial, considerando momentos de seus percursos formativos no PIBID, foi o nosso principal mote discursivo na realização do estudo em caráter mais amplo. Cabe esclarecer que os sujeitos que fazem parte deste estudo, dois sujeitos colaboradores, neste caso, no momento da coleta dos dados, já atuavam como professores de Língua Portuguesa.

Como procedimentos metodológicos adotados, inicialmente, fizemos um levantamento acerca dos egressos do PIBID no período compreendido entre os anos de 2010 a 2014 para a realização dos contatos. Em seguida, partirmos para o esboço do projeto de pesquisa a fim de esclarecer, aos sujeitos da pesquisa, quais eram as pretensões de investigação, baseados no Plano de Trabalho apresentado em nosso Projeto de Pesquisa e nos critérios dispostos para empreendimento do estudo. Em relação aos critérios de escolha para o recrutamento dos sujeitos, utilizamos aspectos voltados à assiduidade e ao cumprimento da maior parte das atividades solicitadas nos momentos em que eram bolsistas do PIBID/NFAL. Entre elas estão as produções de texto acadêmico-científico, as anotações de campo e a elaboração dos diários reflexivos; além da disponibilidade para o acesso aos dados e a participação no estudo. Nesse sentido, foram recrutadas duas egressas, que cumpriram tais requisitos, e se dispuseram a colaborar com a investigação.

Com efeito, o corpus deste estudo é constituído de produções linguístico-discursivas, coletadas pelos pesquisadores no banco de dados do PIBID/Letras/UFAL, por meio de acesso às produções desses sujeitos egressos do PIBID quando eram bolsistas de Iniciação à Docência, considerando-se que esse instrumento era utilizado pela Coordenação à época de suas atuações como pibidianas, que aqui nomeamos de Notas de Campo (NC).

\section{APRESENTAÇÃO, ANÁLISE E DISCUSSÃO DOS DADOS}

Esta parte se presta à apresentação e à análise de alguns dos dados, que julgamos significativos, em acordo com o objetivo geral de nosso estudo, que é investigar, sob o ponto de vista linguístico-discursivo, as argumentações formuladas pelos egressos do PIBID da UFAL, no que diz respeito às suas reflexões, como atuais professores de Língua Portuguesa, quanto às contribuições e às implicações do referido Programa para o seu letramento docente. Há de se compreender que as reflexões dos sujeitos Beatriz e 
Clara $^{3}$, sujeitos de nosso estudo, a partir dos critérios já sinalizados, serão mais bem concebidas a partir da análise de outros instrumentos investigativos, como o questionário aberto que aplicamos. Assim, inicialmente, convém ressaltar que, acessando o Banco de Dados do PIBID-Português, Campus A.C Simões, da UFAL, tivemos contato com as Notas de Campo (NC) e os Relatórios de Estágio Curricular Supervisionado desses sujeitos egressos, que, em razão da delimitação de nossa análise neste texto, deternos-emos à análise de alguns Excertos que constituem as NC.

Contextualmente, o Programa Institucional de Iniciação à Docência (PIBID/UFAL) no locus investigado, considerando o seu Projeto Institucional, no período de 2010 a 2014, no Subprojeto Português, contava com a inserção dos bolsistas, geralmente em grupos constituídos por quatro sujeitos, em escolas credenciadas à Instituição Formadora. A dinâmica do trabalho, introdutoriamente, consistia em rodas de estudo com temas relacionados ao "ensino de Língua Portuguesa"; às "concepções de língua, linguagem e sujeito"; às "abordagens do letramento: nas perspectivas autônoma e ideológica", entre outros que versaram discussões sobre as perspectivas do professor de Língua Portuguesa em vieses de cunho funcionalista, a exemplo das teorias envoltas aos letramentos. Nesses momentos, a Coordenadora de Área propunha leitura de textos teóricos para promover o debate e subsidiar reflexões para que, nos momentos em que esses sujeitos estivessem inseridos nas escolas credenciadas, pudessem estabelecer uma relação praxiológica entre o discutido e o vivenciado.

No acesso às NC, pudemos reconhecer que essas duas pibidianas estavam inseridas em algumas escolas pertencentes à Rede Estadual de Alagoas. Ambas localizadas na parte alta da capital Maceió/AL, sendo uma delas situada geograficamente na parte central, num complexo educacional com várias escolas; e as outras duas escolas estavam alocadas num bairro consideravelmente numeroso, integrando uma das regiões periféricas dessa capital. Na constituição de nosso corpus, analisamos 19 Notas de Campo (sendo I I notas digitadas e 08 notas escritas a punho) do sujeito de pesquisa Beatriz; e I 9 Notas de Campo (todas digitadas) pertencentes ao sujeito de pesquisa Clara. As Notas de Campo objetivavam o registro dos acontecimentos do contexto da sala de aula, na qual as pibidianas estavam inseridas, com vistas ao atendimento ao caráter descritivista das pesquisas etnográficas ou de cunho etnográfico, como é o caso da LA. Tal atividade cotidiana às práticas das pibidianas no locus de suas atuações intencionava que fossem lançadas reflexões (argumentações) sobre as suas condições de estudantes do Curso de Licenciatura em Letras-Português, assumindo-se como professoras em formação inicial.

\footnotetext{
3. Nomes fictícios escolhidos pelos próprios sujeitos desde o momento que faziam parte do grupo do PIBID-Português, Campus A.C.Simões, da Universidade Federal de Alagoas (UFAL). Salientamos que os nomes dispostos, de modo algum, se relacionam diretamente aos nomes dos sujeitos colaboradores desta investigação.
} 


\section{ANÁLISE E DISCUSSÃO DAS NOTAS DE CAMPO (NC)}

Os quatro Excertos, que dispomos a seguir, correspondem a dados autênticos, nos quais são respeitadas as marcas estilísticas das autoras, além do processo pelo qual passaram esses sujeitos para a elaboração de seus letramentos docentes.

\section{EXCERTO ।}

[...]Ao ver a (nome omitido da Supervisora) dar aula, lembrei da (nome omitido da Coordenadora de Área). Era a mesma demonstração de prazer em ensinar, o mesmo comprometimento com o trabalho, com o aprendizado dos alunos. O tempo todo fazendo os alunos pensar, expor suas opiniões, justificar suas escolhas. É tão gratificante ver que há pessoas que exercem a profissão docente com compromisso e responsabilidade. Essa foi uma aula ao mesmo tempo nostálgica e inspiradora que me fez querer ainda mais ser professora (NC/PIBID de Beatriz, 20 I2) (grifos nossos).

Fonte: Dados da Pesquisa, 2019.

Oxcerto I nos possibilita um diálogo com Tardif (2014) no tratamento dos saberes adquiridos na prática experiencial, ou ainda, aqueles que se voltam à rememoração de modelos anteriormente concebidos pelo sujeito, neste caso, em processo de formação inicial docente, como favoráveis à sua futura prática. Reconhecemos, explicitamente, a demarcação desse sujeito em relação à importância de práticas docentes que levem em conta a reflexividade e a interação. $\bigcirc$ ethos enunciativo é apresentado em razão da observação elaborada discursivamente como positiva, filiada a um campo teórico-conceitual que prima por atitudes dialógicas em sala de aula, cuja centralidade na figura do professor se desloca à do aluno, num processo interativo, amalgamando-se.

\section{EXCERTO 2}

Eu percebi q o andamento dessa parte da oficina não correu mto bem. Principalmente pelo fato de os alunos terem acabado de fazer a prova do Saveal. Eles alegavam estar com a mente cansada, pois responderam a quase 200 questões. Acho q a atividade foi válida, eles refletiram, foram críticos, mas poderia ter sido melhor (NC/PIBID de Beatriz, 20।2) (grifos nossos).

Fonte: Dados da Pesquisa, 2019.

Excerto 2 apresenta uma avaliação, mesmo de forma sucinta, sobre uma oficina desenvolvida pelo grupo de pibidianos com o gênero discursivo charge numa das escolas campo de atuação do PIBID. Apesar de apresentar um ethos inicialmente que reflete sobre as variáveis intervenientes na oficina para que não atendesse ao objetivo planejado, Beatriz continua privilegiando em suas NC uma docente em formação inicial que julga importante o desenvolvimento da reflexividade e da criticidade dos sujeitos envolvidos nesse processo. Há de se compreender que, mesmo não tendo o atendimento ao propósito inicialmente traçado para o trabalho com o gênero em foco, em sua escrita reflexiva, Beatriz demonstra maturidade, inclusive, por não omitir fatores que julgou como não tão favoráveis ao desenvolvimento de 
sua atuação como pibidiana. Segundo ela, em outros termos, mesmo em meio a essas variáveis, o gênero em foco possibilitou aos discentes entrar em contato com eventos que promoveram, de alguma forma, práticas de letramento mais voltadas a uma perspectiva ideológica (STREET, 1984).

\section{EXCERTO 3}

Sinceramente, não concordei com o fato de os alunos ficarem fazendo cópias, quando (nome omitido da professora supervisora) poderia esclarecer as tantas dúvidas que eles tinham. Quanto tempo desperdiçado! Lembro que (nome omitido de aluno) até perguntou "Professora, é necessário passar essas questões do livro para o caderno"? Mas, (nome omitido da professora supervisora) disse que sim, pois era isso que o livro pedia. Pensei: Quem é o professor aqui? Ela ou livro? Agora é o livro que instrui? Então, para quê professor em sala de aula? Puxa Lúcia, senti que tudo aquilo não passava de uma estratégia para o tempo passar.

Não quero soar pessimista, crítica (no sentido pejorativo da palavra) e nem ser alguém que aponte uma metralhadora para a professora, apenas me coloco no lugar de meus alunos e sinto por eles. Sei muito bem o que sair de uma escola pública cheia de limitações e com um ensino defasado. (Nome omitido da professora supervisora) precisa urgentemente pensar sua prática. A questão que ela geralmente levanta é que não pode ser comparada a determinados professores, tendo em vista que ela não teve a mesma formação que eles. Isso influi muito, acredito, mas não tanto ao ponto de ser o agente responsável por este ensino deturpado. Minha mãe também é professora e, quando começou a ensinar, tinha apenas o magistério como base; mas independente de suas limitações, ela procurou sempre fazer o diferencial em sala de aula. Mesmo sem ter uma formação superior, a prática de minha mãe não era puramente regida por exercício de metalinguagens. Por isso, eu acredito que todos nós podemos ir muito mais além do que temos ido, basta sermos pessoas determinadas. Creio que tudo aquilo que determinamos no coração, promoverá o resultado esperado (NC/PIBID de Clara, 20 I3) (grifos nossos).

Fonte: Dados da Pesquisa, 2019.

Excerto 3, pertencente à Clara, apresenta diversas passagens em que se pode constatar um ethos enunciativo, com vistas ao desenvolvimento do seu Letramento Docente, durante o processo que integrava o PIBID, considerando as suas atuações nas escolas campo de atuação. Como se pode reconhecer, há presença de modalizadores afetivos, como: sinceramente, além de marcadores desinenciais de primeira pessoa, o que tomamos como marcadores de subjetividade (KOCH, 1987), (CAVALCANTI, 2016), em suas enunciações, como se pode contemplar por meio de: concordei, quero, coloco, acredito... que, mesmo em meio a outros que estejam dispostos em primeira pessoa do singular, estes demonstram um ethos mais ligado à análise de práticas docentes em que esse sujeito estabelece um julgamento, sobretudo, no que diz respeito a práticas mecanicistas, a exemplo da cópia do livro didático, bem como ao posicionamento acerca de práticas de sala de aula que se atenham a exercício de metalinguagens (trecho de seus escritos).

O ethos de Clara se constitui como filiado a uma perspectiva mais funcionalista de língua(gem), em que se pode reconhecer o princípio dialógico subjacente ao seu discurso. Ao trazer o exemplo de sua mãe na condição de professora que, em que no Exceto 3 disposto: mesmo sem ter uma formação superior, adota uma metodologia que não está "diretamente" ligada à formação recebida, em razão de não se ater exclusivamente ao ensino pautado em regras gramaticais. Clara, assim, demarca-se explicitamente a respeito do que julga relevante na relação entre os saberes docentes, sobretudo, os experienciais, em sua prática como docente em formação inicial (TARDIF, 20I4). Portanto, ao demarcar-se como um sujeito 
que busca autonomia em sua prática docente inicial e que rememora outros modelos de professores, a exemplo da sua própria mãe, filia-se a um saber oriundo da experiência advinda dos momentos de reflexão proporcionados pelo PIBID, bem como àquele que demarca um modelo que representa, em sua ótica, em meio às suas ideologias, o que acredita ser pertinente ao seu saber docente. Isso reforça discussões do próprio autor em tela que trata da hibridização de saberes para a constituição dos saberes docentes como saberes profissionais. A seguir, apresentamos o Excerto 4, também pertencente à Clara.

\section{EXCERTO 4}

[...] Observando os alunos, a impressão que tive era que, olhando para todas aquelas regras, eles viam a gramática como um emaranhado de regras e nomenclaturas. Nada além disso! (Nome omitido da professora supervisora) parece não levar em conta tal situação...Parece ignorar a não aprendizagem dos alunos e continua repetindo experiências que há muito tempo deram certo, ou apenas aparentavam que funcionavam. Toda essa situação é muito desagradável para mim, uma professora em processo de formação que pensa (desde já!) além, que acredita piamente no sucesso da escola pública e, consequentemente, dos alunos! (NC/PIBID de Clara, 20I4) (grifos nossos).

Fonte: Dados da Pesquisa, 2019.

Excerto 4, e último, deste campo de análise, é significativo na medida em que, como professora em formação inicial, Clara assume uma concepção de língua(gem) num viés sociointeracionista cujo estudo pressupõe o contato com textos autênticos, de ampla recorrência social (MARCUSCHI, 2008). Ao tratar da aula observada, em que a recorrência às regras gramaticais se fez presente, Clara posiciona-se a respeito de uma prática de ensino pautada em regras descontextualizadas, uma vez que analisa a prática da professora supervisora como atrelada a um modelo que tem se perpetuado há muito na Educação Básica e que, possivelmente, por atender às instâncias de poder de variadas ordens (uma das facetas de um status quo que presta a uma prática de ensino predominantemente voltada à norma padrão, não eleva o sujeito aprendiz em seu processo de ensino e aprendizagem, por vezes, levando-se à (pseudo) crença a respeito de seu sucesso em aulas de Língua Portuguesa.

Nesse sentido, os trechos em destaque deste Enunciado 4 apresentam um ethos que, mesmo insatisfeito mediante a situação vivenciada, tem a consciência de que, em seu processo de formação inicial, almeja contribuir para o: sucesso da escola pública e, consequentemente, dos alunos! Com isso, infere-se que essa abordagem está mais ligada àquilo que vimos tratando, e defendendo, no âmbito dos modelos de letramento. Nesses termos, tal modelo se presta àquele mais centrado no ideológico, embora, há de se salientar que não se possa deixar de contemplar, nas próprias práticas de sala de aula, o ensino da metalinguagem. Nesse mesmo sentido, compreendemos que de modo isolado corresponde a um modelo exclusivamente autônomo de letramento, o que pode ser fator impeditivo ao desenvolvimento de uma perspectiva crítico-reflexiva cuja demanda, sobremaneira, versa a requerida apresentação de juízos de valor na vida cidadã de forma ampla, que agrega práticas de linguagem híbridas, mestiças, movediças e multifacetadas (STREET, 1984), (CAVALCANTI, 20I6) e (MOITA-LOPES, I996, 2006). 
Como pudemos perceber, as NC apresentadas neste tópico de discussão correspondem, a partir das análises realizadas, às enunciações autênticas dos sujeitos da pesquisa nos momentos em que estavam em contato, em suas formações iniciais, com práticas de estudo, reflexão, observação e, por vezes, de aplicação de oficinas. Tais expedientes, ligados aos processos crítico-reflexivos proporcionados pelo PIBIDLetras/UFAL, mostraram-se como relevantes às práticas iniciais dessas professoras em formação.

\section{CONSIDERAÇÕES FINAIS}

Os dados dispostos, compilados nesta discussão, serviram-nos para analisar as argumentações enunciadas pelos sujeitos inseridos no PIBID, período 2010 a 2014, a respeito de suas atuações como pibidianas, por meio de práticas de escrita reflexiva, como docentes em formação inicial do Curso de Letras-Português. No recorte temporal eleito, 2010 a 2014, a partir dos dados a que tivemos acesso, notadamente, esses sujeitos eram constantemente motivados a refletir sobre as práticas de sala de aula, considerando-se os momentos de estudo, de rodas de socialização das práticas observadas e de suas atuações propriamente ditas nas escolas credenciadas ao PIBID no locus investigado.

Como tratamos, os dois sujeitos de nosso estudo se dispuseram a subsidiar as suas anotações (NC) em razão de nossas questões norteadoras e dos objetivos que pretendíamos inicialmente atender com tal empreitada investigativa. Os dois sujeitos, no instrumento questionário aberto aplicado, em relação às suas impressões sobre o PIBID, avaliaram-no como um Programa Institucional que fez a "diferença" no modo de conceber o espaço da sala de aula, metaforicamente concebendo-o como "uma caixinha de surpresas". Obviamente, tal percepção acerca desse espaço, que demanda saberes diversificados sobre a ação docente, se afina àquilo já anunciado por nós a partir de Tardif (2014). Nesse prisma, a articulação entre saberes docentes, oriundos de aportes teórico-conceituais no âmbito da formação inicial somados aos saberes experienciais, resultam numa espécie de letramento docente. Tal condição é tida, neste âmbito de discussão, como imprescindível à constituição do ethos docente na medida em que esses sujeitos - em processos de formação inicial -, em práticas letradas diversificadas, foram constantemente solicitados a argumentarem acerca de questões atinentes aos contextos variados de ensino e, principalmente, sobre si, conferindo à sua prática o status de tradicional ou inovadora, com base no campo epistemológico em que se filiaram ideologicamente.

Em alguns dos trechos analisados, pôde-se constatar, por meio de um ethos que assumidamente se entende como dialógico, uma concepção de língua pautada num viés discursivo, cujas condições de produção e os sujeitos sociohistóricos e discursivos são constantemente enaltecidos. Essa demarcação subjetiva (retórico-enunciativa) se deu em suas NC, em decorrência desses sujeitos apresentarem reflexões consistentes sobre as concepções de língua, linguagem e sujeito - das tendências formalistas às 
funcionalistas. Nesse tocante, podem ser evidenciados trechos em que avaliam posturas de sala de aula de cunho mais estruturalista, cuja metalinguagem, segundo elas, era tratada de modo a não contemplar a concepção de língua e de sujeito com a qual se filiavam.

O Programa Institucional de Iniciação à Docência (PIBID), no contexto investigado, não apenas cumpriu o desiderato de possibilitar que os sujeitos pibidianos vivenciassem situações do universo escolar e, em específico, da sala de aula de Língua Portuguesa, mas, principalmente, favorecesse o desenvolvimento de seus Ethe docentes que se anunciam por sujeitos que, mesmo diante das demandas da contemporaneidade, estão em constante reflexão sobre os seus fazeres laborais, o que implica um pensamento articulado entre a Docência e os conhecimentos linguísticos que dão suporte às atuações como docentes. Por fim, vale salientar a necessidade, no âmbito da formação docente, inicial e continuada, de um imbricamento entre os saberes relativos ao letramento acadêmico com aqueles ligados ao letramento docente que, nesses termos, se assumem como mais amplos. Portanto, acreditamos que os objetivos traçados para o estudo foram em grande parte atendidos, bem como houve subsídio enunciativodiscursivo por parte dos sujeitos da pesquisa para respondermos às questões que nortearam a discussão em voga.

\section{REFERÊNCIAS}

BAKHTIN, M (V.N. Volochínov). Marxismo e filosofia da linguagem. São Paulo: HUCITEC, 198I[1979).

BAKHTIN, M. Gêneros do discurso. In: Estética da criação verbal: introdução e tradução do russo Paulo Bezerra; prefácio à edição francesa Tzvetan Todorov. 4. ed. São Paulo: Martins Fontes, 2003 [1992].

BRASIL. Ministério da Educação. Coordenação de Aperfeiçoamento de Pessoal de Nível Superior CAPES. EDITAL MEC/CAPES/FNDE - Seleção pública de propostas de projetos de iniciação à docência voltados ao Programa Institucional de Iniciação à Docência - PIBID. 12 Dez. 2007. Disponível em: http://www.capes.gov.br/images/stories/download/editais/Edital_PIBID.pdf Acesso em: I I/I I/2017.

CAVALCANTI, R. J. de S. O ensino da argumentação: uma experiência didática com o artigo de opinião no curso de Letras. Dissertação de Mestrado, Programa de Pós-Graduação em Educação do Centro de Educação da Universidade Federal de Alagoas, 2010.

CAVALCANTI, R. J. de S. Análise textual-argumentativa de processos de retextualização: um cotejo entre a produção oral e escrita de alunos do curso médio técnico e alunos do proeja ensino médio. Tese de Doutorado, Programa de Pós-Graduação em Letras e Linguística da Universidade Federal de Alagoas, 2016.

CRESWELL, J. W. Projeto de pesquisa: métodos qualitativo, quantitativo e misto. 2.ed. Porto Alegre: Bookman, 2007.

DUCROT, O. O dizer e o dito. Campinas: Pontes, 1987. 
FIAD, R.; MIRANDA, F. D. S. S. 20 I4. Letramentos digitais e acadêmicos em contexto universitário: investigando práticas letradas em um Curso de Letras de uma universidade pública. Revista Colineares, v. I: 3 I-50. Disponível em: http://periodicos.uern.br/index.php/colineares/article/view/937. Acesso em: $13 / 10 / 2017$

KLEIMAN, A.; BALTAR, M. (Orgs.). Letramento e formação de professores. Palhoça (SC), Ed. UNISUL, v. 8, n. 3, set./dez. 2008, p.407-652.

KLEIMAN, A. (Org.). A formação do professor: perspectivas da Linguística Aplicada. São Paulo: Mercado de Letras, 200I.

KLEIMAN, A. Os significados do letramento: uma nova perspectiva sobre as práticas da escrita.

Campinas: Mercado de Letras, 1995.

KLEIMAN, A.; MATENCIO, M. de L. M. Letramento e formação do professor: práticas discursivas, representações e construções do saber. São Paulo: Mercado de Letras, 2005.

KLEIMAN, A. Os significados do letramento: uma nova perspectiva sobre as práticas da escrita. 7.ed. Campinas: Mercado de Letras, 2008.

KLEIMAN, A. B.; ASSIS, J. A. (orgs.). Significados e ressignificações do letramento: desdobramentos de uma perspectiva sociocultural sobre a escrita. Campinas: Mercado de Letras, 2016.

KOCH, Ingedore G. V. Dificuldades na leitura/produção de textos: os conectores interfrásticos. In: CLEMENTE, Elvo (Orgs.). In: Lingüística aplicada ao ensino de português. Porto Alegre: Mercado Aberto, 1987, p. 83-98.

KOCH, I. G.V. Argumentação e linguagem. I I.ed. São Paulo: Cortez, 2008 [1 984].

LÜDKE, M.; ANDRÉ, M. E.D.A. Pesquisa em educação: abordagens qualitativas. São Paulo: EPU, 1986. MARCUSCHI, L. A. Produção textual, análise de gênero e compreensão. São Paulo: Parábola, 2008.

MEYER, B. A arte de argumentar: com exercícios corrigidos. São Paulo: WMF Martins Fontes, 2008.

MOITA-LOPES, L. P. da. Oficina de lingüística aplicada: a natureza social e educacional dos processos de ensino/aprendizagem de línguas. São Paulo: Mercado de Letras, 1996.

MOITA-LOPES, L. P. (Org.). Por uma Lingüística Aplicada Indisciplinar. São Paulo: Parábola, 2006.

NEVES, José Luiz. Pesquisa qualitativa - características, usos e possibilidades, 1996. Disponível em: . Acesso em: 2/2/2009.

PERELMAN, C; OLBRECHTS-TYTECA, L. O tratado da argumentação: a nova retórica. São Paulo: Martins Fontes, 2005 [1958].

REBOUL, Olivier. Introdução à retórica. São Paulo: Martins Fontes, 2004 [1998].

ROJO, R. (Org.). Alfabetização e letramento: perspectivas linguísticas. São Paulo: Mercado de Letras, 2009 . 
ROJO, R. Letramentos múltiplos, escola e inclusão social. São Paulo: Parábola, 2009b.

SANTOS, L. de F. Lendo, escrevendo e refletindo sobre docência: vivências e possibilidades no Pibid/Letras. In: LUIS, S.; SANTOS, L. F.; SILVA, S. (Orgs.). Universidade e escola: diálogos sobre formação docente. Recife: Ed. Universitária da UFPE: 20।2, p. 209-23 I.

SANTOS, L. de F. Produção de textos na universidade: em busca de atitudes ativas e táticas. 2007. Tese de Doutorado. Programa de Pós-Graduação em Letras e Linguística. Universidade Federal de Alagoas, 2007.

SIGNORINI, I. (Org.). Investigando a relação oral/escrito e as teorias do letramento. São Paulo: Mercado de Letras, 2006.

STREET, B. Letramentos sociais: abordagens críticas do letramento no desenvolvimento, na etnografia e na educação. Trad. Marcos Bagno. São Paulo: Parábola, 2014.

STREET, B. Literacy in theory and practice. London. Cambridge University Press, 1984.

TARDIF, M. Saberes docentes e formação profissional. Petrópolis, RJ: Vozes, 2014.

VIANA, C. A. D. et al. Do letramento aos letramentos: desafios na aproximação entre letramento acadêmico e letramento do professor. In: KLEIMAN, A. B.; ASSIS, J. A. (Orgs.). Significados e ressignificações do letramento: desdobramentos de uma perspectiva sociocultural sobre a escrita. Campinas: Mercado de Letras, 2016, p.27-59.

VÓVIO, C.; SITO, L.; DE GRANDE, P. B. (Orgs.). Letramentos: rupturas, deslocamentos e repercussões em pesquisas em linguística aplicada. Campinas: Mercado das Letras, 2010.

\section{COMO CITAR ESSE ARTIGO}

\section{Associação Brasileira de Normas Técnicas (ABNT)}

CAVALCANTI, Ricardo Jorge de Sousa; SANTOS, Lúcia de Fátima. A argumentação no processo de formação inicial docente: reflexões dos egressos do PIBID Letras/Português da Universidade Federal de Alagoas. Debates em Educação, Maceió, v. I2, p. 246-262, dez. 2020. ISSN 2 I 75-6600. Disponível em: https://www.seer.ufal.br/index.php/debateseducacao/article/view/l 0070. Acesso em: dd mmm. aaaa.

\section{American Psychological Association (APA)}

Cavalcanti, R., \& Santos, L. (2020). A argumentação no processo de formação inicial docente: reflexões dos egressos do PIBID Letras/Português da Universidade Federal de Alagoas. Debates em Educação, I 2(Esp), 246-262. doi: https://doi.org/10.28998/2 175-6600.2020vI2nEspp246-262 